\title{
RAPID ENLARGEMENT OF A DISTAL ARCH ANEURYSM AFTER ENDOVASCULAR STENT-GRAFTING FOR PSEUDOANEURYSM: CASE REPORT
}

\author{
Toshihiro Ohata, MD, Tetsuo Sakakibara, MD, Hiroshi Takano, MD, Hironori Izutani, MD, and Yoichi Inoue, MD, Osaka, Japan
}

Recently, the transluminal placement of endovascular stentgraft prostheses has offered a largely successful alternative approach to the treatment of thoracic aortic aneurysm that is less invasive and presents a lower risk than the standard operative method, ${ }^{1,2}$ but cardiac surgeons using the new method have not yet fully determined the optimum indications for applying it. We report a case in which we had to replace a transluminally implanted stent-graft prosthesis in a patient who had rapid enlargement of a distal aneurysm 3 years after the implantation to close off a pseudoaneurysm of the distal anastomosis.

Clinical summary. A 65-year-old man was admitted to our hospital with a diagnosis of chronic bronchitis. He had undergone graft replacement of the distal arch for a dilatation of type IIIb chronic thrombosed aortic dissection through a median sternotomy in April 1993. A pseudoaneurysm appeared around the distal anastomosis site 3 years later. An endovascular stent-graft was implanted to close off the pseudoaneurysm in August 1996. The stent-graft was composed of a stainless-steel Z-shaped stent attached to a woven polyester graft material with a series of interrupted 5-0 polypropylene sutures. Perigraft leakage around the pseudoaneurysm was observed on enhanced computed tomography (CT) on the eighth postoperative day, but the patient was discharged soon after, when its disappearance was confirmed angiographically.

The patient had sudden severe back and chest pain and came to our hospital for examination on June 8, 1999. A chest CT scan showed no significant increase in aneurysmal diameter around the stent-graft since its endovascular implantation 3 years earlier. Electrocardiography showed no ischemic change, and the patient was released. On June 22, a high fever $\left(>39^{\circ} \mathrm{C}\right)$ and the same pains appeared, and he was admitted to our hospital with a diagnosis of chronic bronchitis. The leukocyte count was $6100 / \mathrm{mm}^{3}$. No bacteria was found in blood or sputum culture. A chest CT scan showed a reenlargement of

From the Division of Cardiovascular Surgery, Osaka Police Hospital, Osaka, Japan.

Received for publication March 16, 2000; accepted for publication May 18, 2000.

Address for reprints: Toshihiro Ohata MD, Division of Cardiovascular Surgery, Osaka Police Hospital, 10-31 Kitayamacho, Tennoji-ku, Osaka 543-0035, Japan (E-mail: TOHATA@aol.com).

J Thorac Cardiovasc Surg 2000;120;824-6

Copyright () 2000 by The American Association for Thoracic Surgery

$0022-5223 / 2000 \$ 12.00+0 \quad \mathbf{1 2 / 5 4 / 1 0 8 6 9 6}$

doi: $10.1067 / \mathrm{mtc} .2000 .108696$ the distal arch aneurysm and aortic wall thickening. The aneurysm had dilated from 4.6 to $6.1 \mathrm{~cm}$ in diameter (Fig 1, $A$ and $B$ ). Because the aneurysm had dilated so rapidly, we decided to remove the stent-graft and the previous graft and to implant another graft in an open-chest procedure. The recurrent perigraft leakage around the distal anastomosis site was suspected to be the cause of aneurysmal reenlargement.

We performed a total arch replacement with a 4-branched graft (24 $\mathrm{mm}$ in diameter) under selective cerebral perfusion. The ascending aorta and right atrium were cannulated through a remedian sternotomy, and cardiopulmonary bypass was established. After moderate systemic hypothermia was reached $\left(28^{\circ} \mathrm{C}\right)$, the ascending aorta was crossclamped, the aorta was opened, and cold blood cardioplegic solution was administered antegradely. We performed an additional retrograde infusion of blood cardioplegic solution. The cranial edge of the stent-graft was reached at the root of the left subclavian artery, as shown on preoperative chest x-ray film (Fig 2). The stent jacket adhered firmly to the native aortic wall and the previous graft. The intima surrounding the distal anastomosis site was the color of dark blood and was overlaid in some places with thrombus. The intima around the proximal anastomosis site was intact. After removing the stent-graft and the previous graft under selective cerebral perfusion, we first performed the distal anastomosis at the proximal descending thoracic aorta, $2 \mathrm{~cm}$ distal to the previous anastomosis site. After reconstructing the left subclavian artery, we performed a proximal anastomosis at the ascending aorta and released the aortic crossclamp. We completed the total arch replacement after reconstructing the brachiocephalic and left common carotid artery. The patient was weaned from cardiopulmonary bypass without difficulty and had an unremarkable recovery.

Bacteriologic study of the specimen taken from the excised aortic wall tissue and the previous graft revealed no bacteria. Pathologic examination of the resected aortic wall showed mucoid degeneration of the media of the aorta but no bacterial colony. Postoperative aortography showed no remarkable findings. The patient was discharged on postoperative day 20.

Discussion. Since Dotter ${ }^{3}$ initially proposed the concept of a transluminally placed endovascular graft in 1969, there have been several reports on the clinical use of balloon- or selfexpandable stent-grafts. ${ }^{1,2,4}$ Although agreeing on the utility of this procedure, these studies also discuss its problems and relatively frequent complications: the need for a second procedure, transient chest pain, pleural effusion, and perigraft leakage. ${ }^{1,2,4}$ Perigraft leakage in particular is a major complication of endovascular stent-graft implantation. ${ }^{5}$ One report related that perigraft leakage with persistent flow in the 

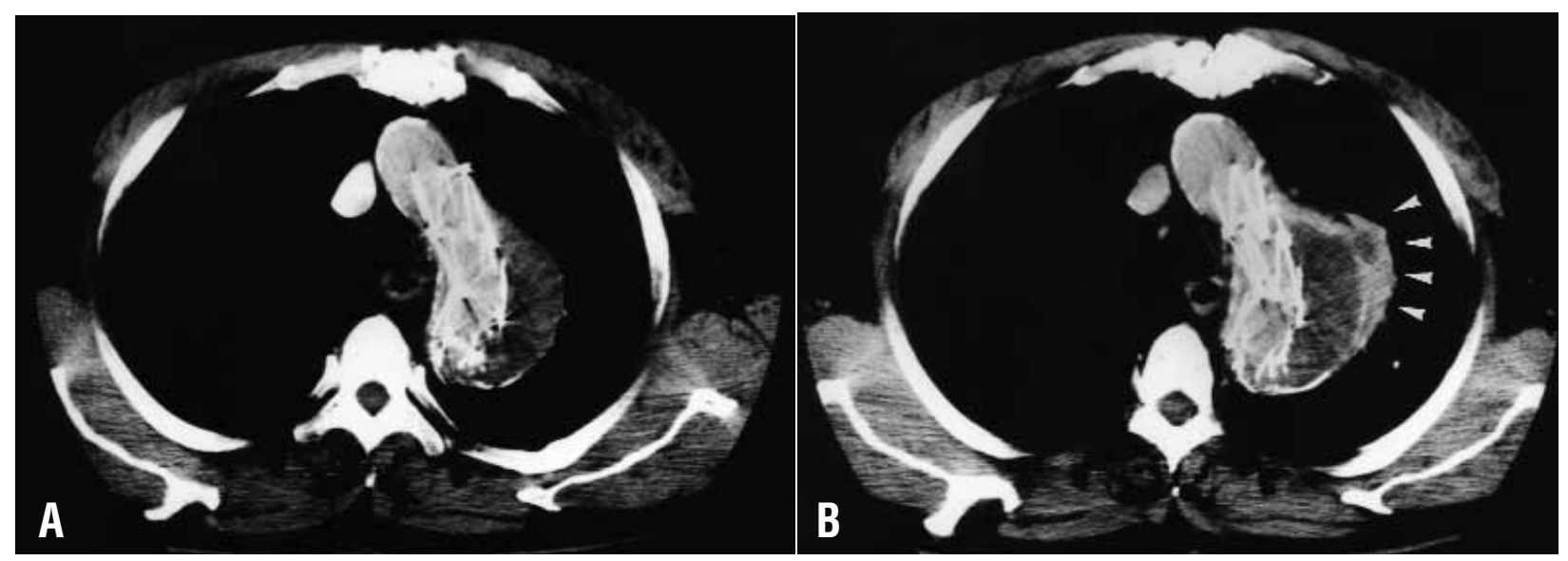

Fig 1. The CT findings of the enlargement of the distal arch aneurysm around the stent-graft before (A) and after (B) the rise in the patient's fever. Aortic wall thickness and enlargement of distal arch aneurysm are seen in $\mathbf{B}$.

aneurysmal sac might cause an aneurysm to rupture and could be fatal. ${ }^{6}$ This could have been the outcome in our case; we simply want to emphasize that the residual perigraft leakage resulted in a rapid enlargement of the pseudoaneurysm in the late postoperative phase. Although we made an error in judgment for a disappearance of perigraft leakage around the pseudoaneurysm on postoperative angiography, perigraft leakage should have been completely treated if it was suspected on the postoperative CT scan.

Dake and colleagues ${ }^{7}$ reported that aneurysm size had decreased after endovascular stent-graft implantation in $48 \%$ of their patients, showed no change in $26 \%$, and had increased in $26 \%$. Because aneurysm pressure after endovascular exclusion has been reported to be lower than that found in the radial artery, ${ }^{8}$ perigraft leakage might cause it to rise in the patient with aneurysmal enlargement and cause the aneurysm to rupture. Early perigraft leakage should be treated immediately and not ignored or neglected if it was detected with postoperative CT scanning or angiography. If detected, surgical graft replacement after stent-graft removal, additional endovascular stent-graft implantation, or coil embolization $^{9}$ should be selected. For patients with no decrease in aneurysmal size, however, there is no consensus on which strategy should be selected. Transluminal endovascular stent-grafting will thus become a still safer and more reliable alternative treatment for those patients only when cardiac surgeons arrive at a consensus on which strategy is the most appropriate for this problem.

\section{REFERENCES}

1. Parodi JC, Palmaz JC, Barone HD. Transfemoral intraluminal graft implantation for abdominal aortic aneurysms. Ann Vasc Surg 1991;5:491-9.

2. Dake MD, Miller DC, Semba CP, Mitchell RS, Walker PJ, Liddel RP. Transluminal placement of endovascular stent-grafts for the treatment of descending thoracic aortic aneurysms. N Engl J Med 1994;331:1729-34.

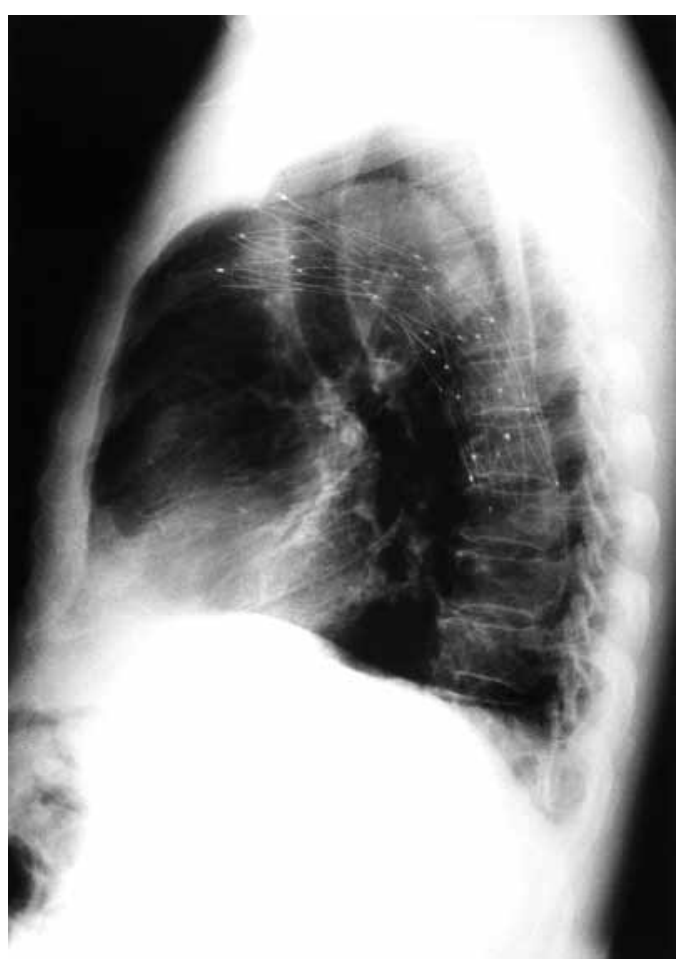

Fig 2. The preoperative chest x-ray film showed that the cranial edge of the stent-graft was reached at the root of the left subclavian artery.

3. Dotter CT. Transluminally-placed coilspring endoarterial tube grafts. Long-term patency in canine popliteal artery. Invest Radiol 1969;4:329-32.

4. Kato M, Matsuda T, Kaneko M, et al. Experimental assessment of newly devised transcatheter stent-graft for aortic dissection. Ann Thorac Surg 1995;59:908-15. 
5. Schurink GWH, Aarts NJM, van Baalen JM, Kool LJS, van Bockel JH. Stent attachment site-related endoleakage after stent graft treatment: an in vitro study of the effects of graft size, stent type, and atherosclerotic wall changes. J Vasc Surg 1999;30:658-67.

6. Lumsden AB, Allen RC, Chaikof EL, et al. Delayed rupture of aortic aneurysm following endovascular stent grafting. Am J Surg 1995;170:174-8.

7. Dake MD, Miller DC, Mitchell RS, Semba CP, Moore KA, Sakai
$\mathrm{T}$. The first generation of endovascular stent-grafts for patients with aneurysm of the descending thoracic aneurysm. J Thorac Cardiovasc Surg 1998;116:689-704.

8. Chuter T, Ivancy K, Malina M, et al. Aneurysm pressure following endovascular exclusion. Eur $\mathrm{J}$ Vasc Endovasc Surg 1997;13:85-7.

9. Kato N, Semba CP, Dake MD. Embolization of peri-graft leaks following endovascular stent-graft treatment of aortic aneurysms. J Vasc Intervent Radiol 1996;7:805-11 